\title{
A Cost Model for Integrated Logistic Support Activities
}

\author{
M. Elena Nenni \\ Department of Industrial Engineering, University of Naples Federico II, Piazzale Tecchio 80, 80125 Naples, Italy
}

Correspondence should be addressed to M. Elena Nenni; menenni@unina.it

Received 27 September 2012; Accepted 13 December 2012

Academic Editor: Shey-Huei Sheu

Copyright (C) 2013 M. Elena Nenni. This is an open access article distributed under the Creative Commons Attribution License, which permits unrestricted use, distribution, and reproduction in any medium, provided the original work is properly cited.

\begin{abstract}
An Integrated Logistic Support (ILS) service has the objective of improving a system's efficiency and availability for the life cycle. The system constructor offers the service to the customer, and she becomes the Contractor Logistic Support (CLS). The aim of this paper is to propose an approach to support the CLS in the budget formulation. Specific goals of the model are the provision of the annual cost of ILS activities through a specific cost model and a comprehensive examination of expected benefits, costs and savings under alternative ILS strategies. A simple example derived from an industrial application is also provided to illustrate the idea. Scientific literature is lacking in the topic and documents from the military are just dealing with the issue of performance measurement. Moreover, they are obviously focused on the customer's perspective. Other scientific papers are general and focused only on maintenance or life cycle management. The model developed in this paper approaches the problem from the perspective of the CLS, and it is specifically tailored on the main issues of an ILS service.
\end{abstract}

\section{Introduction}

A specific type of after-sale contract is expanding beyond the boundaries of military, where it was initially introduced. It offers the customer an Integrated Logistic Support (ILS) service [1], to improve system's efficiency and availability for the life cycle. The Contractor Logistic Support (CLS) core business is the design, construction, and installation of complex hi-tech systems, which are produced in a limited number and usually require a long time to market. Basically, a customer enters into partnership with the CLS because its specific and sometimes exclusive skills for the system's life cycle management. The CLS commits itself for a very protracted period, frequently for the entire system's life cycle, to guarantee the performance at the service level. It requires the elaboration of a management framework in order to optimize costs and achieve the CLS's business objectives.

In this context, the aim of this paper is to provide an approach to support the CLS management in the budget phase for ILS activities. The approach should be used to run a comprehensive examination of expected benefits, costs, and savings under alternative ILS strategies. The main feature of the proposed model is to explore the problem of the life cycle management for the CLS.

The paper begins with a short literature review in order to point out as in the ILS context only the development of specific cost figures that has been addressed up to now. Moreover, papers deal only with the perspective of the customer. Section 3 is devoted to delineate the proposed approach, and in Section 4 we go through the cost model as the core of our proposal. In the last section, we present a real industrial application.

\section{Literature Review}

Decisions support systems should be based on appropriate models in order to optimize the overall costs. For this purpose many authors have spent themselves in developing fitting cost models: Kaufman [2] has provided a first original contribution on the structure of life cycle costs in general; other authors [3-5] have focused more specifically on costs of operations and support $(\mathrm{O} \& \mathrm{~S})$ phase with the aim to optimize preventive maintenance policies. Hatch and Badinelli [6] have instead studied the way of combining two 
TABLE 1: Comparison between LCM and ILS (proposed approach).

\begin{tabular}{ll}
\hline Life cycle cost & Integrated Logistic Support \\
\hline Perspective of the customer & Perspective of the contractor \\
Addressed early design and production stage & $\begin{array}{l}\text { Addressed early design and production stage } \\
\text { Used in the budgeting and operating phase }\end{array}$ \\
Used in the acquisition phase & $\begin{array}{l}\text { Aim to reduce the total cost of operations and support } \\
\text { Aim to reduce the total cost of ownership }\end{array}$ \\
Cost of developing, producing, using, and retiring a particular item & $\begin{array}{l}\text { Cost forentive and corrective maintenance, penalty cost, } \\
\text { and cost for Delay Time }\end{array}$ \\
\hline
\end{tabular}

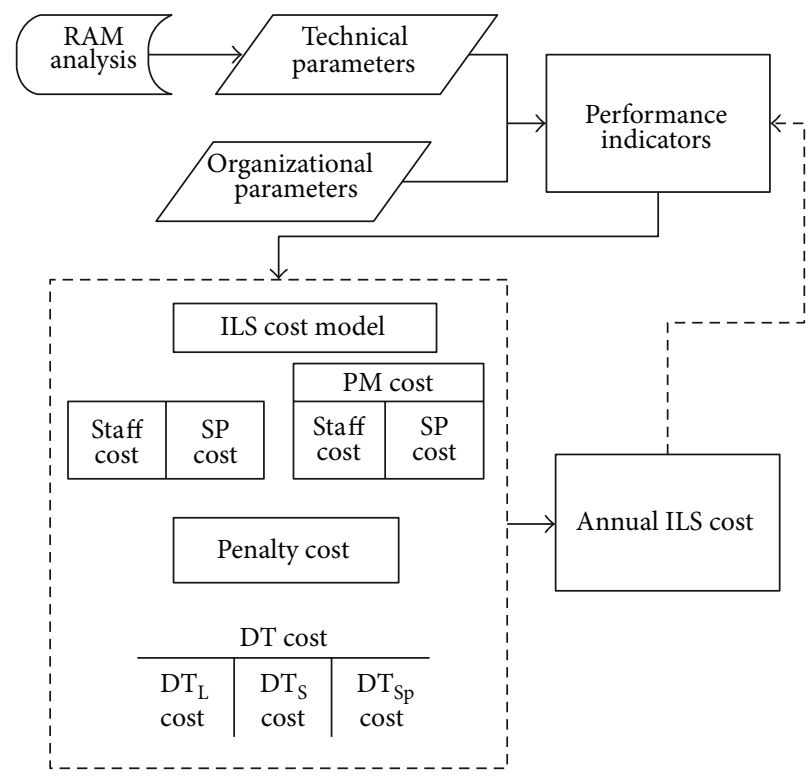

FIGURE 1: The proposed approach.

conflicting components, life cycle cost (LCC) and system availability (A), in a single objective function. Finally, many documents from the military report on criteria for calculating system availability and main cost categories that should be considered [7].

It is easy to note that all the contributions partially address the issue of developing an integrated approach to optimize the ILS cost. They only deal with some cost figures and most especially are lacking in considering the problem from the perspective of the CLS actor. Instead, our proposal takes into consideration all the costs involved in ILS. It is not really original in all its specific parts, but it develops some original cost figures and combines some contributions from previous sources together. Moreover, it allows CLS to run some scenarios to compare different performance and strategies. At the end of this short review, we want to present a comparison between the proposed approach and the well-known life cycle management (LCM). Basically LCM concerns with the balance of investment between acquisition costs and full life cycle costs to maximize the customer utility. The main discrepancies with the approach proposed in this paper are reported in Table 1.

\section{The Proposed Approach}

Before going through the proposed cost model, it is necessary describe some assumptions. The first one concerns the area in which it runs. The ILS process is usually involved in (i) design and production (D\&P), (ii) operation and support (O\&S), and (iii) retirement and disposal (R\&D), but the O\&S phase is the longest and can be the most costly $[8,9]$. That is the reason for which O\&S issues should be addressed in early stages, and it is particularly interesting for CLS. The specific goal of the paper is, thus, the provisioning of annual cost of ILS activities for the O\&S phase.

The second assumption is that we study the cost model at the level of the whole system under the ILS contract (radar, ship, airplane, etc.). We even consider as already carried out the RAM analysis [10] to provide the main technical parameters for the cost model.

In Figure 1 the proposed approach is completely described.

(1) Data input is technical parameters from the RAM analysis and organizational parameters.

(2) The preprocessing step calculates performance indicators on the base of data input. 
TABLE 2: Main technical parameters for the cost model from the RAM analysis.

\begin{tabular}{ll}
\hline Parameters & Description \\
\hline MTBF & Mean time between failures \\
MTTRS & Mean time to restore the system \\
MTBP & Mean time between preventive maintenance \\
MTTP & Mean time to preventive \\
\hline
\end{tabular}

TABLE 3: ILS performance indicators.

\begin{tabular}{ll}
\hline Indicators & Description \\
\hline MTBM & Mean time between maintenance \\
MDT & Mean down time \\
$A_{o}$ & Operational availability \\
\hline
\end{tabular}

TABLe 4: Penalty cost for poor performance.

\begin{tabular}{|c|c|c|}
\hline Indicators & Target & Penalty cost $\left(C_{P}\right)$ \\
\hline MTBM $\leq$ & $\mathrm{MTBM}_{1}$ & $P_{\text {Мтвм }}$ \\
\hline $\mathrm{MTBM} \geq$ & $\mathrm{MTBM}_{2}$ & $P_{\text {Мтвм }}^{\prime}$ \\
\hline $\mathrm{MDT} \geq$ & $\mathrm{MDT}_{\mathrm{T}}$ & $P_{\mathrm{MDT}}$ \\
\hline$A_{o} \leq$ & $A_{T}$ & $P_{A}$ \\
\hline$A_{o} \leq$ & 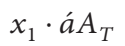 & $P_{A}^{\prime}$ \\
\hline$A_{o} \leq$ & $x_{2} \cdot a A_{T}$ & $P_{A}^{\prime \prime}$ \\
\hline
\end{tabular}

(3) The core of the approach is the cost model that calculates the annual ILS cost depending on the performance level.

(4) The last step lets a trade-off between the performance and the ILS cost or provides an analysis of the of different ILS strategies on both cost and performance.

\section{The Cost Model}

Let's go through the core of the approach analyzing the cost model. We present firstly the data input and then all the cost figures.

4.1. The Data Input and the Performance Evaluation. In order to develop a fitting cost model, we have initially coped with the problem of individuating the main parameters of the model that is reported in Table 2 .

Additional parameters are then related to the organizational issues. Basically, we take into consideration a skill factor $(\mathrm{SF} \geq 1)$, decreasing down to the asymptotic value of 1 as experience, training, and expertise possessed by the ILS staff grows. The SF affects on the time to restore the system. The Delay Time is introduced for analyzing specifically the reason because an activity could be delayed. It is split up in Logistic Delay Time $\left(\mathrm{DT}_{\mathrm{L}}\right)$, in Staff Delay Time $\left(\mathrm{DT}_{\mathrm{S}}\right)$, and in Spare Parts Delay Time $\left(\mathrm{DT}_{\mathrm{Sp}}\right)$.

Finally, the ILS performance is evaluated through indicators in Table 3.
According to the main reference [10], we include formulas for ILS indicators as follow:

$$
\mathrm{MTBM}=\frac{1}{(1 / \mathrm{MTBF})+(1 / \mathrm{MTBP})},
$$

MDT

$$
\begin{gathered}
=\frac{\left(\mathrm{SF} \cdot \mathrm{MTTRS}^{-}\left(\mathrm{DT}_{\mathrm{L}}+\mathrm{DT}_{\mathrm{S}}+\mathrm{DT}_{\mathrm{Sp}}\right)\right) / \mathrm{MTBF}}{(1 / \mathrm{MTBF})+(1 / \mathrm{MTBP})} \\
+\frac{\mathrm{MTTP} / \mathrm{MTBP}}{(1 / \mathrm{MTBF})+(1 / \mathrm{MTBP})} \\
A_{o}=\frac{\mathrm{MTBM}}{\mathrm{MTBM}+\mathrm{MDT}} .
\end{gathered}
$$

4.2. The Cost Figures. Now, we go through the cost model through the investigation of the cost figure that is split up in cost for preventive maintenance (PM) and cost for corrective maintenance (CM).

The PM and CM costs are both affected mainly by staff and spare parts (SP) costs. Concerning the staff cost, it is closely related to the time to perform the maintenance activity, MTTP or MTTRS. As result, the annual cost for preventive maintenance is

$$
C_{\mathrm{PM}}=\left(\left(c_{\mathrm{Sh}} \cdot n \cdot \mathrm{MTTP}\right)+c_{\mathrm{SP}}\right) \cdot \frac{\mathrm{OT}}{\mathrm{MTBP}}
$$

where $c_{\mathrm{Sh}}$ is the average hourly cost for an employee, $n$ is the number of persons in staff, $c_{\mathrm{SP}}$ is the average cost for spare parts and material, and the Operating Time (OT) is the period when a system is working.

Analogously the annual cost for corrective maintenance is

$$
C_{\mathrm{CM}}=k \cdot\left(\left(c_{\mathrm{Sh}} \cdot n \cdot \mathrm{MTTRS}\right)+c_{\mathrm{SP}}\right) \cdot \frac{\mathrm{OT}}{\mathrm{MTBF}},
$$

where $k>1$ increases the cost to take into account several complications that often occur with a breakdown.

An additional cost category in the model is related to the penalty cost for poor performance (CP) that is based on the ILS indicators and calculated as shown in Table 4. The introduction of a penalty cost allows us to consider the trade-off between costs and performance in accordance with recommendations by Hatch and Badinelli [6].

The MTBM should be in an optimal range $\left[\mathrm{MTBM}_{1}\right.$, $\mathrm{MTBM}_{2}$ ] to avoid the system stops too frequently and a poor use of preventive maintenance too. The MDT exceeding its target reveals a problem of maintainability. Finally, penalty cost related to $A_{o}$ is a continuous function at times as in Table 4 , where $x_{2}>x_{1}$ and both are $<1$ and $P_{A}^{\prime \prime}>P_{A}^{\prime}$.

The last cost figure in the model concerns the Delay Time. We do not consider that cost is incurred directly because an activity is delayed. In fact, it is just in penalty cost through the MDT indicator. But we have developed ad hoc a cost figure that links Delay Times to the investment in their improvement or to maintain them constant as follow:

$$
C_{\mathrm{DT}}=\gamma \cdot \ln \left(\frac{\mathrm{DT}^{0}}{\mathrm{DT}}\right) \text {. }
$$



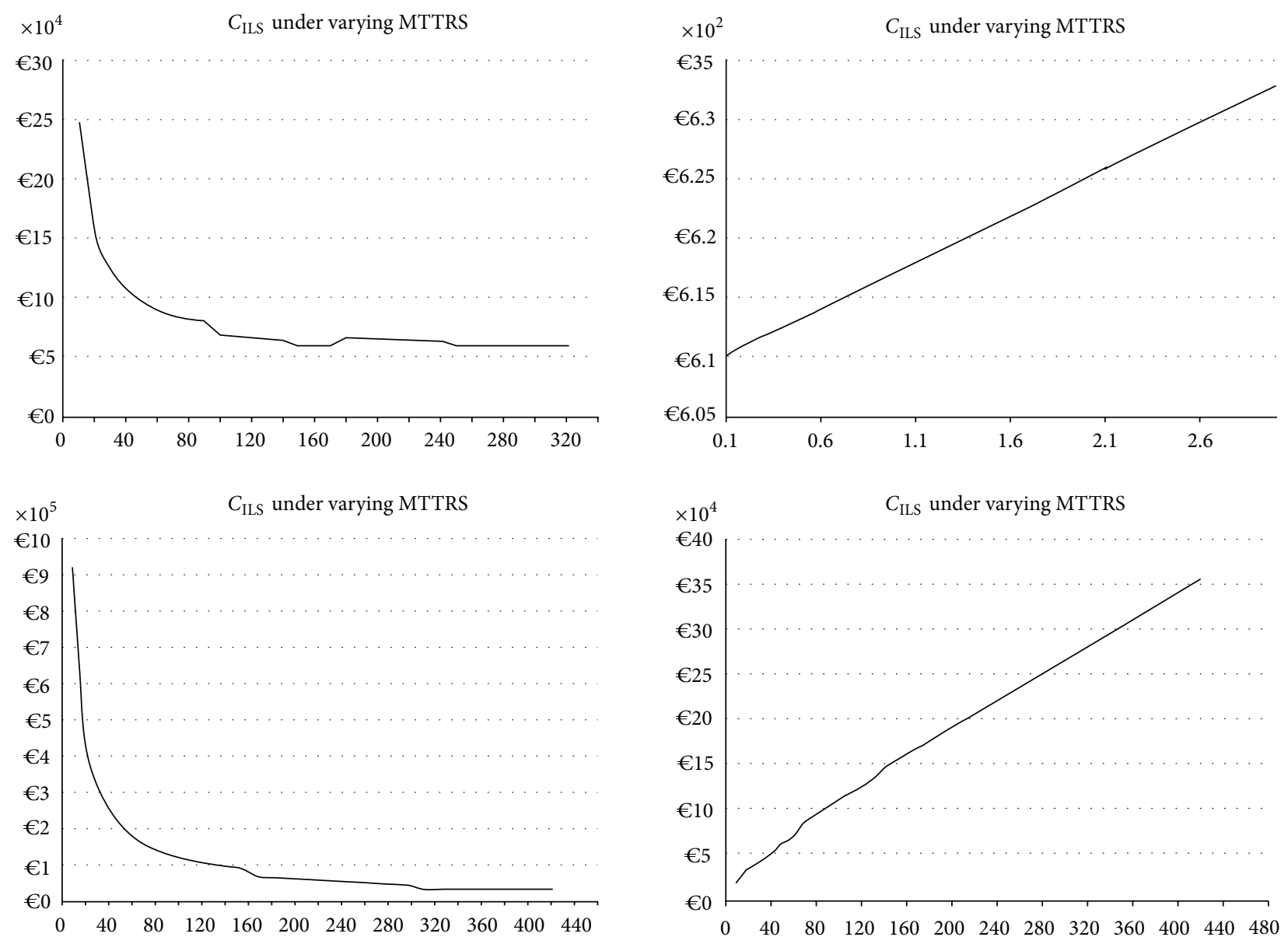

Figure 2: $C_{\text {ILS }}$ under the variation of MTBF, MTTRS, MTBP, and MTTP.

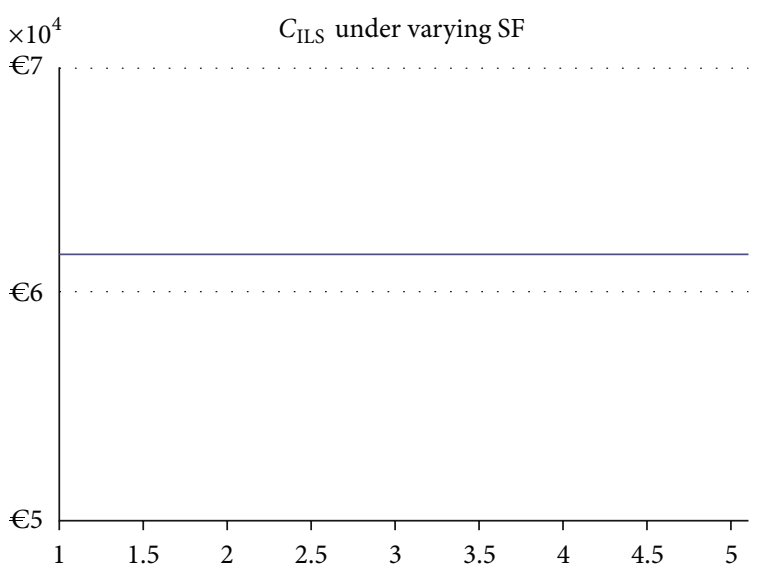

FIGURE 3: $C_{\text {ILS }}$ under the variation of SF.

Considering that the cost for performing an activity decreases monotonously while duration grows, CDT is a logarithm function as in (4), where $\mathrm{DT}^{0}$ could be estimated as a value of DT at the beginning of the year if there is no further investment. DT is the expected value for the current year and $\gamma$ is a constant calculated on the basis of a relationship between investment and DT that could be known. That is, if the investment to halve DT $\left(c_{0,5}\right)$ is known, then

$$
\gamma=\frac{c_{0,5}}{\ln 2}
$$

Now the annual cost function $\left(C_{\text {ILS }}\right)$ can be formulated in the following way:

$$
C_{\mathrm{ILS}}=C_{\mathrm{PM}}+C_{\mathrm{CM}}+C_{P}+C_{\mathrm{DT}_{\mathrm{L}}}+C_{\mathrm{DT}_{\mathrm{S}}}+C_{\mathrm{DT}_{\mathrm{Sp}}} .
$$

\section{Industry Application}

The idea in this paper was developed in a research center located in an area of Italy richly populated by companies providing the military with complex systems as radars or missiles, in which the importance of the ILS is growing daily. In Table 5 we report just a short example of the cost 

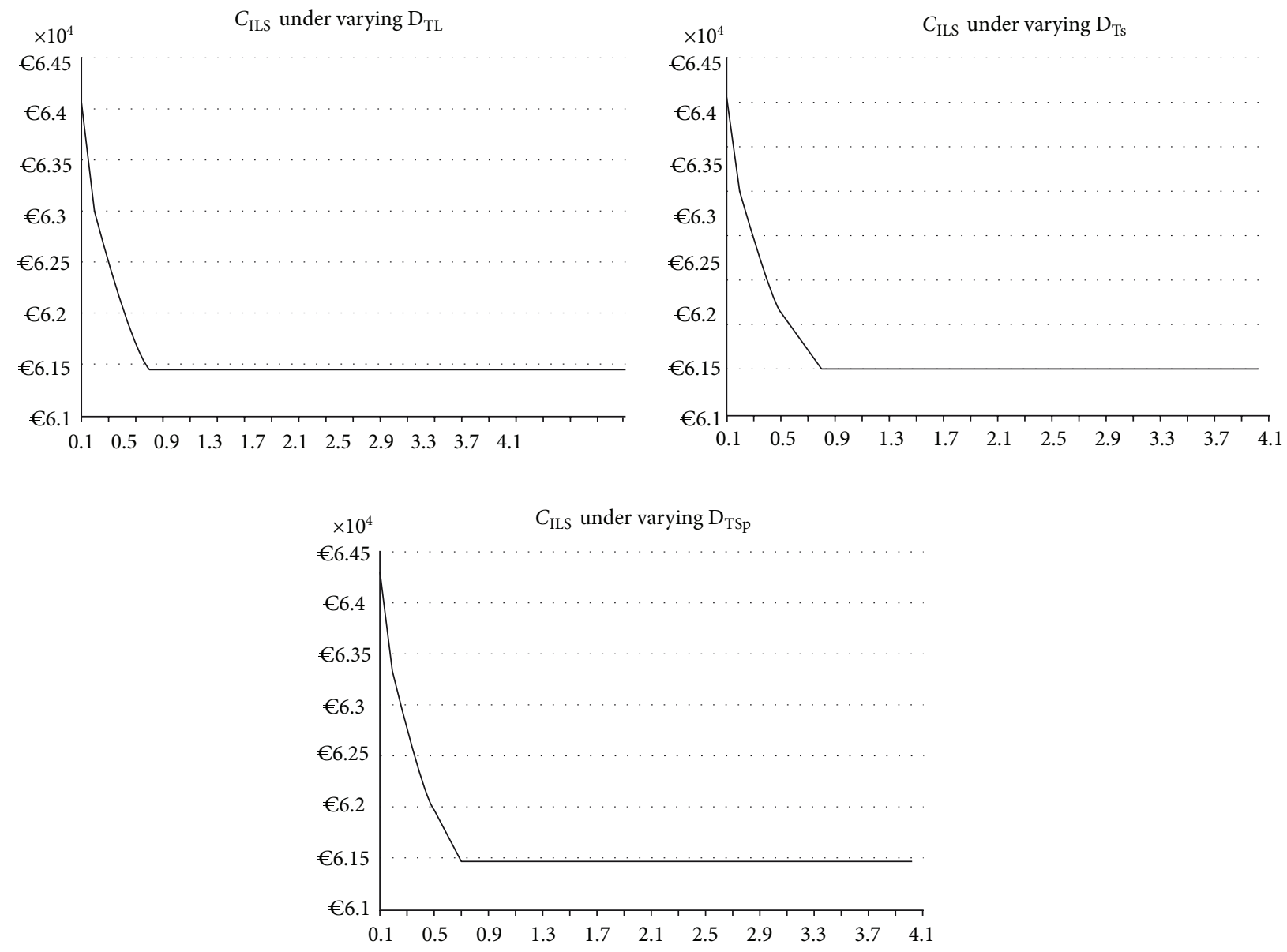

FIGURE 4: $C_{\text {ILS }}$ under the variation of $\mathrm{D}_{\text {Ts }}$.

model application in this industry. It was built by extracting a minimum set of data from a real plan of ILS activities for supporting radars provided by a CLS to the air force of a country in the Mediterranean area. In the basic scenario, the CLS can calculate the CILS as $€ 61.708$ that represents a very comprehensive evaluation of the annual cost for ILS activities including the original cost item CDT and combining the trade-off between costs and system availability.

The CLS is now supported during the negotiating and budgeting phases as well as during the whole system's life cycle through a most useful cost optimization. In fact, the CLS is typically the designer and constructor of the hi-tech system and he manages all the technical and organizational parameters. By changing them, CLS can analyze different ILS scenarios and have an instant reply to the way in which a parameter affects the annual ILS cost. In Figure 2 we report the $C_{\text {ILS }}$ under the variation of MTBF, MTTRS, MTBP, and MTTP. Trends suggest that investments for increasing MTBF over 100 hours are probably not justified by the saving on the $C_{\text {ILS }}$ that holds almost steady. The same happens for MTBP over 200 hours. Insteading, increasing MTTRS and MTTP means increases linearly even the $C_{\text {ILS }}$.

Figure 3 shows an invariance of $C_{\text {ILS }}$ from the skill factor. Finally, in Figure 4 we can see that under varying Delay Times, the trend of $C_{\text {ILS }}$ becomes constant after a few. Instead, decreasing the DT values involves an investment cost. But it is interesting that cost grows very slowly, and for Delay Times point of view, $C_{\text {ILS }}$ increases of about just $€ 3.000$ or $€ 4.000$. It obviously depends on the $c_{0,5}$ that is quite low.

\section{Concluding Remarks}

The annual cost function $\left(C_{I L S}\right)$ just formulated meets all the proposed requirements. Indeed, it provides annual cost of ILS activities for the O\&S phase. Moreover, the introduction of specific cost categories, as penalty cost and cost for Delay Time, addresses the requirement of approaching the problem from the pers of the CLS. Finally, the cost model supports CLS for decisions in the budget phase and better for assessing the effectiveness of planning under alternative ILS strategies. 
TABLE 5: Example of the cost model-basic scenario.

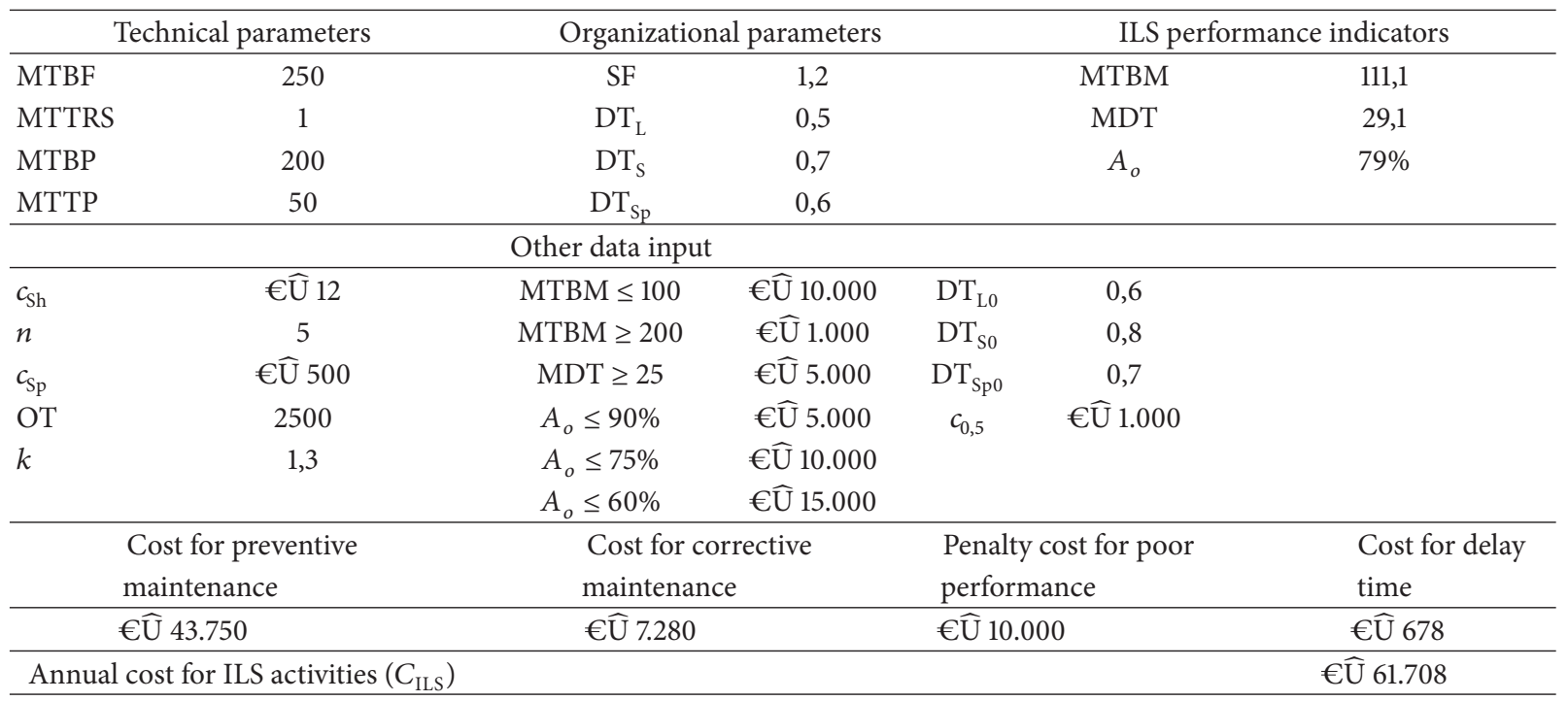

More generally the cost model has been developed to be used to approach the CLS's costs optimization and risk management. The purpose of the author is just to go in depth into the two last issues in next research work.

\section{References}

[1] Department of Defense (DOD), Directive 4100.35, Development of Integrated Logistics Support for Systems and Equipments, Department of Defense, Arlington, Va, USA, 1970.

[2] R. J. Kaufman, "Life cycle costing: a decision-making tool for capital equipment acquisition," Cost and Management, vol. 2, pp. 21-28, 1970.

[3] C. M. F. Lapa, C. M. N. A. Pereira, and M. P. De Barros, "A model for preventive maintenance planning by genetic algorithms based in cost and reliability," Reliability Engineering and System Safety, vol. 91, no. 2, pp. 233-240, 2006.

[4] D. Chen and K. S. Trivedi, "Optimization for condition-based maintenance with semi-Markov decision process," Reliability Engineering and System Safety, vol. 90, no. 1, pp. 25-29, 2005.

[5] K. Woohyun, A. Suneung, and J. Yang, "Determining the periodic maintenance interval for guaranteeing the availability of a system with a linearly increasing hazard rate: industry application," International Journal of Industrial Engineering, vol. 16, no. 2, pp. 126-134, 2009.

[6] M. L. Hatch and R. D. Badinelli, "Concurrent optimization in designing for logistics support," European Journal of Operational Research, vol. 115, no. 1, pp. 77-97, 1999.

[7] Department of Defense (DOD), Guide for Achieving Reliability, Availability and Maintainability, Department of Defense, Arlington, Va, USA, 2005.

[8] J. Choi, "O\&S cost growth," in Proceedings of the 3rd Annual Navy/Marine Corps Cost Analysis Symposium, Gray Research Center, Quantico, Va, USA, 2009.

[9] Y. Asiedu and P. Gu, "Product life cycle cost analysis: state of the art review," International Journal of Production Research, vol. 36, no. 4, pp. 883-908, 1998.
[10] N. H. Mortensen, U. Harlou, and A. Haug, "Improving decision making in the early phases of configuration projects," International Journal of Industrial Engineering, vol. 15, no. 2, pp. 185194, 2008. 


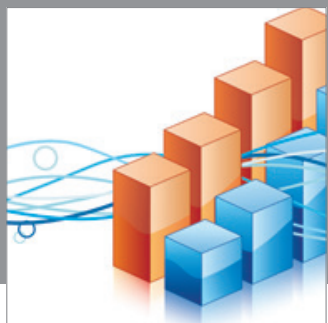

Advances in

Operations Research

mansans

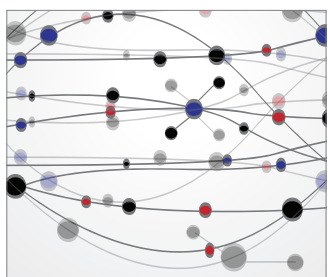

The Scientific World Journal
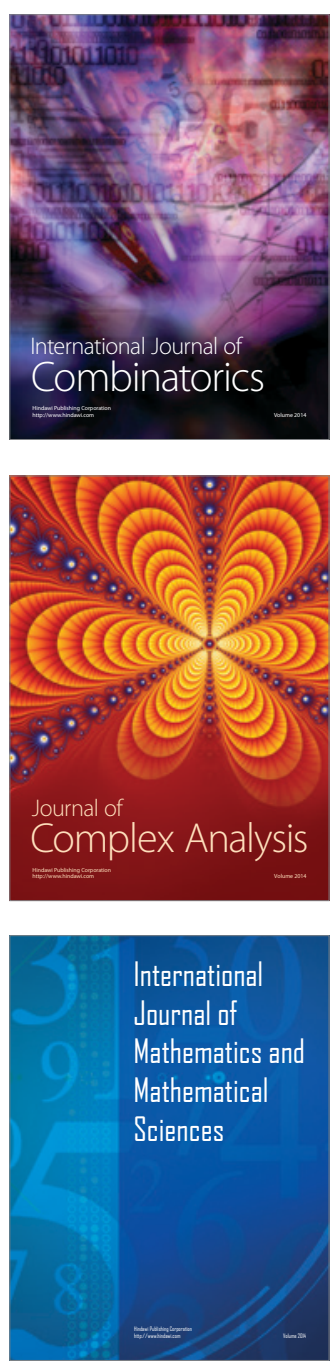
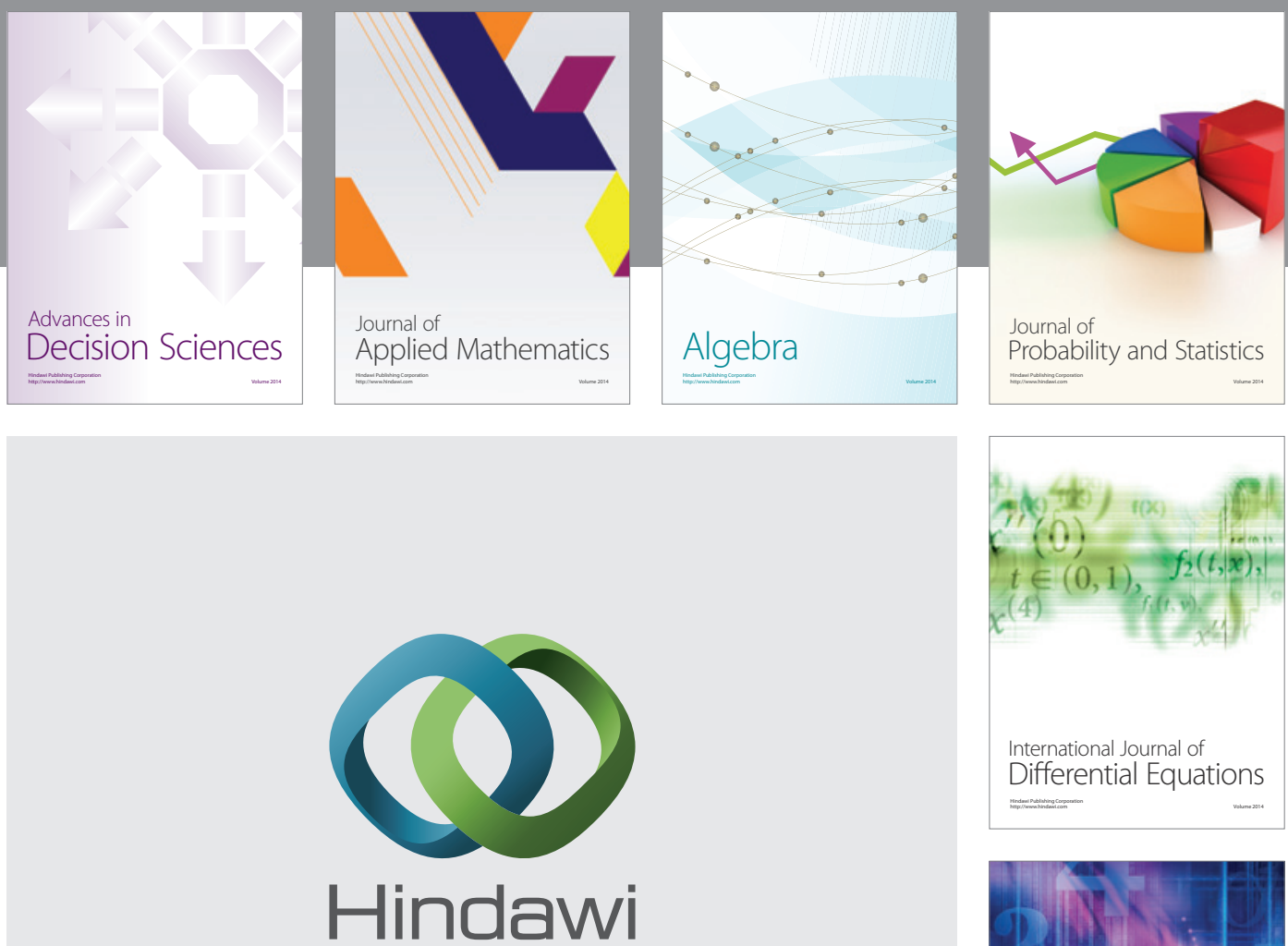

Submit your manuscripts at http://www.hindawi.com
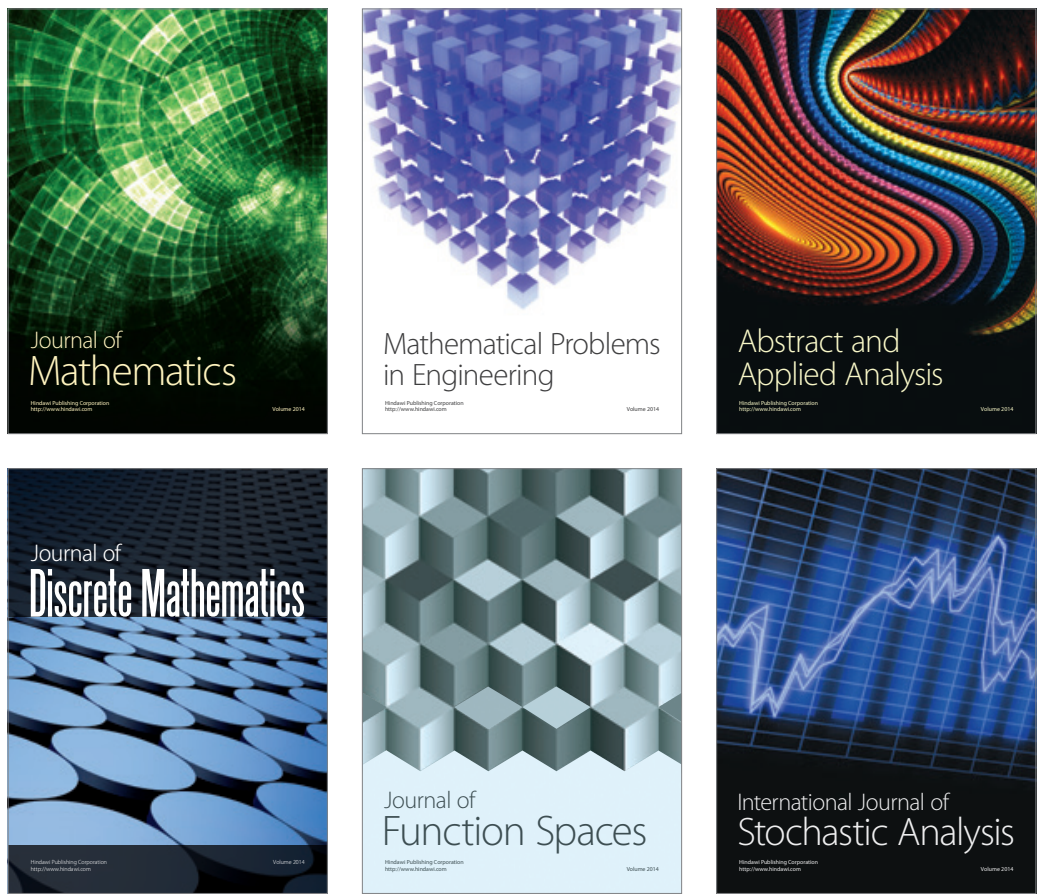

Journal of

Function Spaces

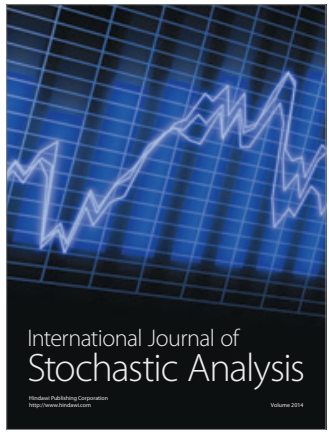

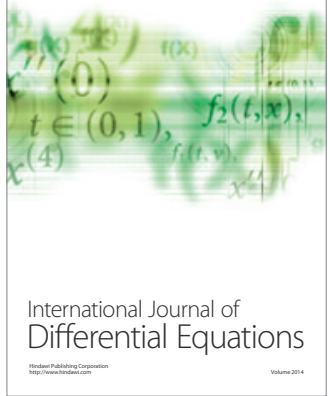
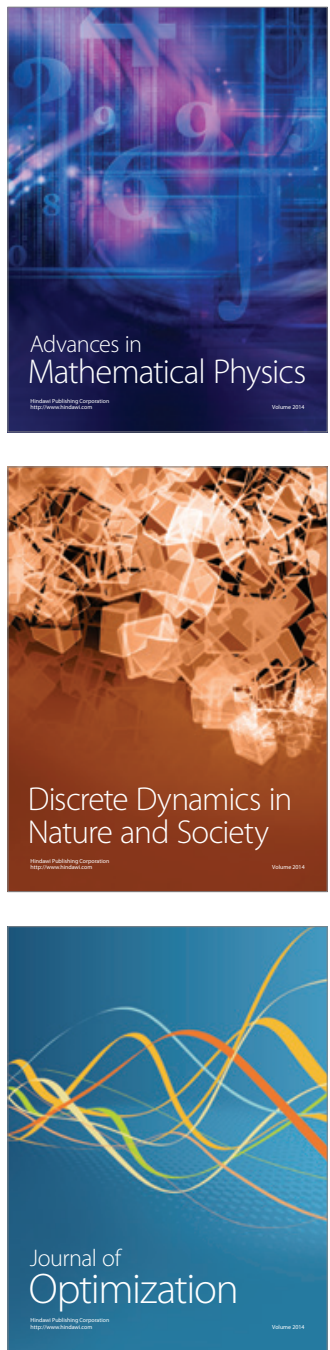